\title{
SEPARAÇÃO DA MULHER E SEU ACOMPANHANTE NO NASCIMENTO POR CESÁREA: UMA VIOLAÇÃO DE DIREITO*
}

\author{
Adaiana Fátima Almeida ${ }^{1}$, Odaléa Maria Brüggemann² ${ }^{2}$ Roberta Costa ${ }^{3}$, Carolina Frescura Junges ${ }^{4}$
}

\begin{abstract}
RESUMO: Objetivo: desvelar a experiência da mulher e seu acompanhante que tiveram o direito de compartilhar o nascimento de seu filho violado. Método: pesquisa qualitativa, exploratório-descritiva, foram entrevistadas 13 puérperas e seus companheiros, de janeiro a julho de 2016 em maternidade pública localizada no Planalto Catarinense. A análise se deu através da análise de conteúdo com o auxílio do software Atlas.ti 7.0. Resultados: são apresentados em três categorias: Experiência da mulher em não ter acompanhante na sala cirúrgica; Experiência do acompanhante em aguardar o nascimento sozinho; e o Poder dos profissionais de saúde sobre a cena do nascimento. Conclusão: o estudo evidenciou que os sentimentos negativos acerca da experiência, uma vez que a mulher se sentiu desamparada sem a presença do seu companheiro e ele desapontadopor não vivenciar o nascimento do filho. O principal fator para essa separação foi à atitude dos profissionais de saúde que ainda impedem a presença de um acompanhante na sala cirúrgica.
\end{abstract}

DESCRITORES: Enfermagem obstétrica; Cesárea; Apoio social; Parto Humanizado.

\section{SEPARATION OF THE WOMAN AND HER COMPANION DURING CESAREAN SECTION: A VIOLATION OF THEIR RIGHTS}

\begin{abstract}
Objective: to reveal the experience of the woman and her companion whose right to share the birth of their child was violated. Method: qualitative, exploratory-descriptive research. Interviews were held with 13 puerperal women and their companions, between January and July 2016, in a public maternity hospital located in the tablelands of Santa Catarina. Analysis took place through content analysis using the Atlas.ti 7.0 software. Results: these are presented in three categories: The woman's experience in not having her companion in the operating room; The companion's experience in waiting for the birth alone; and The power of the health professionals over the birth scenario. Conclusion: the study evidenced the negative feelings regarding the experience; the woman felt unsupported due to the absence of her companion, and the companion felt disappointed because of not experiencing the birth of their child. The main factor behind this separation was the attitude of the health professionals, who continue to impede the companion's presence in the operating room.

DESCRIPTORS: Obstetric Nursing; Cesarean: Social Support; Humanizing Delivery.
\end{abstract}

\section{SEPARACIÓN DE LA MUJER Y SU ACOMPAÑANTE EN NACIMIENTO POR CESÁREA: UNA VIOLACIÓN DE DERECHOS}

RESUMEN: Objetivo: Develar la experiencia de la mujer y su acompañante cuyo derecho a compartir el nacimiento de su hijo fue violado. Método: Investigación cualitativa, exploratorio-descriptiva. Fueron entrevistadas 13 puérperas y sus parejas, de enero a julio de 2016 en maternidad pública del Planalto Catarinense. Se aplicó análisis de contenido, con ayuda de software Atlas.ti 7.0. Resultados: Están presentados en tres categorías: Experiencias de la mujer al no tener acompañante en quirófano; Experiencia del acompañante aguardando el nacimiento en soledad; y Poder de los profesionales de salud en el marco del nacimiento. Conclusión: Se evidenciaron los sentimientos negativos de la experiencia, habiéndose sentido desamparada la mujer sin la presencia de su pareja, y él decepcionado por no participar del nacimiento de su hijo. El principal factor de la separación fue la actitud de los profesionales de salud que aún impiden la presencia de acompañantes en el quirófano.

DESCRIPTORES: Enfermería Obstétrica; Cesárea; Apoyo Social; Parto Humanizado.

*Artigo extraído da dissertação intitulada: Experiência de Mulheres e Acompanhantes que não permaneceram juntos durante a cesárea. Programa de Pós-Graduação em Enfermagem. Universidade Federal de Santa Catarina. 2016.

${ }^{1}$ Enfermeira Obstetra. Mestre em Enfermagem. Enfermeira Obstetra no Centro Obstétrico no Hospital Tereza Ramos. Lages, SC, Brasil.

Enfermeira Obstetra. Doutora em Tocoginecologia. Docente Permanente no Programa de Pós-Graduação em Enfermagem na Universidade Federal de Santa Catarina. Florianópolis, SC, Brasil.

${ }^{3}$ Enfermeira. Doutora em Enfermagem. Docente Adjunta Ildo Departamento de Enfermagem, do Programa de Pós-Graduação em Enfermagem e do Programa de Pós-Graduação em Gestão do Cuidado em Enfermagem na Universidade Federal de Santa Catarina, Florianópolis, SC, Brasil.

${ }^{4}$ Enfermeira. Doutora em Enfermagem. Enfermeira Assistencial doHospital Universitário Polydoro Ernani de São Thiago, UFSC. Florianópolis, SC, Brasil.

Autor Correspondente:

Adaiana Fátima Almeida

Recebido: 08/06/2017

Instituição vinculada: Secretaria de Saúde do Estado de Santa Catarina

Finalizado: 21/12/2017

Av. Papa João XXIII, n 740 - 88505-200, Lages, Santa Catariana, Brasil

E-mail: adaiana.f.almeida@gmail.com 


\section{INTRODUÇÃO}

A presença do acompanhante de escolha da mulher é uma forma simples e eficaz de humanizar o nascimento, beneficia a mulher, bebê, equipe de saúde e sociedade ${ }^{(1-5)}$. No Brasil, em 2005, houve a publicação da Lei $n^{\circ} 11.108$ (Lei do Acompanhante), que obriga os serviços de saúde do Sistema Único de Saúde (SUS) e da rede conveniada a permitir a presença do acompanhante de escolha da mulher durante todo o período de trabalho de parto, parto e pós-parto imediato ${ }^{(6)}$.

Entretanto, em várias instituições as parturientes não têm seu direito assegurado, permanecendo sozinhas $^{(1,7)}$.A presença do acompanhante é alvo de críticas e dúvidas por parte de alguns profissionais da saúde, sobre o quanto essa presença estaria contribuindo ou dificultando os cuidados prestados a mulher durante o trabalho de parto e parto, e em relação ao seu comportamento e preparo para participar desse processo na instituição $0^{(6-9)}$.

Fatores como contexto social, política de saúde do país e sua legislação, e principalmente a filosofia da maternidade, podem contribuir para estimular e permitir à presença do acompanhante na cena do nascimento ${ }^{(4,10-11)}$.

Durante muitos anos o impedimento de homens como acompanhantes em maternidades foi uma prática adotada. Porém ainda existem instituições que permitem apenas a presença de outras mulheres como acompanhantes ${ }^{(12)}$. Alguns profissionais e instituições acreditam que a presença masculina tira a privacidade das demais parturientes, fato relacionado com a ambiência inadequada, privando muitos casais de vivenciar o nascimento de seus filhos ${ }^{(8)}$.

Muitos profissionais que consideram o modelo biologicista de atenção ao nascimento o ideal, julgam a presença do acompanhante um problema. Atualmente esse cenário vem se modificando em razão de transformações na formação dos profissionais que prezam por um modelo de atenção voltado a assistência humanizada ${ }^{(13)}$.

Para alguns profissionais da área da saúde, que prestam assistência a mulher na sala cirúrgica, ainda é difícil aceitar a presença do acompanhante, por isso esse é o local onde sua presença é menos frequente. Eles consideram que o ambiente é inadequado para recebê-lo, visto que a cesárea se trata de uma cirurgia de grande porte e o acompanhante não está acostumado às condutas adotadas durante o procedimento, podendo interferir ou interpretar indevidamente as ações dos profissionais. O despreparo emocional também é um dos fatores apontados pelos profissionais para justificar a exclusão do acompanhante no nascimento ${ }^{(7-11)}$.

Desse modo, o objetivo desse estudo foi desvelar a experiência da mulher e seu acompanhante que tiveram o direito de compartilhar o nascimento de seu filho violado. Justifica-se a importância dessa pesquisa pelo fato de que a presença do acompanhante de escolha da mulher, em todo o processo gravídico-puerperal, garantido por Lei, é essencial para que esse momento seja vivenciado e compartilhado por ambos de forma positiva.

\section{- MÉTODO}

Pesquisa qualitativa, exploratória e descritiva. Desenvolvida em uma Maternidade pública localizada no Planalto Catarinense, na qual a presença do acompanhante de escolha da mulher é permitida durante todo o trabalho de parto e parto, entretanto na cesárea essa prática não é constante.

Participaram da pesquisa 13 mulheres submetidas à cesárea e seus companheiros. A identificação dos participantes se deu através do livro de registro do Centro Obstétrico (CO). Foram incluídas as mulheres que estavam no puerpério imediato, maiores de 18 anos, que tiveram o companheiro/ pai do bebê como acompanhante durante todo o trabalho de parto, mas não tiveram a presença dele na cesárea. Foram excluídas as mulheres com dificuldade (psíquicas e comportamentais) para responder a entrevista e que o bebê foi a óbito. 
Após a identificação das puérperas elegíveis foram convidados os acompanhantes que, segundo os critérios de inclusão, eram companheiros e também pais dos bebês, maiores de 18 anos, que permaneceram durante o trabalho de parto, mas que não puderam acompanhar o nascimento por cesárea, sendo excluídos aqueles com dificuldade para responder ao questionário.

O primeiro contato com as puérperas foi realizado no Alojamento Conjunto (AC), após o aceite, os acompanhantes também foram convidados. Apenas duas puérperas e seus acompanhantes preferiram que a entrevista fosse realizada no domicílio, os demais optaram por ser entrevistados na maternidade.

As entrevistas ocorreram de janeiro a julho de 2016, realizadas individualmente e separadamente, preservando a privacidade de cada participante, áudio gravadas na íntegra. Logo após a coleta, as entrevistas foram transcritas e revisadas pela própria pesquisadora, quando se iniciou a análise das informações colhidas. A finalização da coleta de dados ocorreu quando houve a saturação dos dados ${ }^{(14)}$.

A análise dos dados foi realizada seguindo o método de Análise de Conteúdo, para isso foi utilizado o software Atlas.ti 7.0, como uma ferramenta de auxílio na análise e organização dos dados ${ }^{(15-16)}$.

A análise de conteúdo possui três etapas: 1. Pré-analise ou organização do material, composta por três passos: escolha da documentação, formulação das hipóteses e a elaboração de indicadores que fundamentarão a interpretação final dos dados. Nessa etapa as entrevistas foram inseridas no Atlas.ti 7.0, o corpus da pesquisa constitui uma unidade hermenêutica (hermeneuticunit), posteriormente ocorreu a leitura flutuante dos dados, para a familiarização dos pesquisadores com os dados obtidos e assim elaborar as hipóteses referentes aos objetivos da pesquisa e o recorte das informações relevantes ${ }^{(15)}$.

2. Exploração do material ou codificações, os dados brutos foram transformados sistematicamente e agregados em unidades, as quais permitiram uma descrição exata das características pertinentes ao conteúdo. Nesse momento, no Software Atlas.ti 7.0 foram criados códigos (codes), após interligados aos depoimentos (quotations) com o mesmo significado, e a organização desses códigos constituiu as famílias (families).

3. Tratamento dos resultados (inferência e interpretação). Busca tornar os dados significativos e válidos, tem como objetivo a busca do sentido mais abrangente das respostas, feito mediante sua ligação a outros conhecimentos anteriormente obtidos ${ }^{(15)}$. Nessa etapa, o Atlas.ti possibilitou visualizar em diversas perspectivas um conjunto de dados ou documentos e a codificação que surge na análise em forma de diagramas e figuras ${ }^{(16)}$.

A pesquisa foi desenvolvida respeitando os aspectos éticos da Resolução no 466/2012 do Conselho Nacional de Saúde ${ }^{(17)}$,sendo que o projeto foi aprovado pelo Comitê de Ética em Pesquisa com Seres Humanos em 07 de dezembro de 2015 sob o parecer número: 1.353.667.

Para garantir a proteção e anonimato dos participantes, conforme disposto no Termo de Consentimento Livre e Esclarecido, assinado por todos os participantes, as entrevistas foram identificas pelas letras $\mathrm{P}$ (Puérpera) ou $\mathrm{A}$ (Acompanhante) e por um algarismo arábico, conforme a sequência de realização das mesmas.

\section{RESULTADOS}

\section{Características dos participantes}

As 13 puérperas entrevistadas tinham idade entre 18 e 36 anos, nove eram primíparas, duas haviam passado por cesárea anteriormente e as outras duas já tinham vivenciado parto normal. Quanto à escolaridade, oito haviam concluído o ensino médio, quatro possuíam ensino fundamental incompleto e uma estava cursando nível superior. Todas viviam com o companheiro há pelo menos seis meses e no máximo 20 anos. Apenas três conheciam a Lei do Acompanhante, oito relataram nunca ter ouvido falar da Lei e duas relataram pensar que o acompanhante poderia entrar apenas no parto normal.

Os 13 acompanhantes tinham idade entre 19 e 38 anos, nove haviam concluído o ensino médio, dois não concluíram o ensino fundamental, um havia concluído o ensino superior e outro estava cursando. 
Todos participaram de pelo menos uma consulta ou realização de exames durante o pré-natal, no que se refere ao conhecimento acerca da Lei do Acompanhante, 10 relataram não conhecer, dois conheciam e um conhecia parcialmente, pois acreditava que não era permitida sua presença na cesárea.

Dessa forma, percebe-se que a maioria dos participantes não tinha conhecimento sobre a existência da Lei do Acompanhante, reforçando a necessidade de difundir as informações sobre esse direito, principalmente no pré-natal, visto que a maioria das mulheres teve a presença do acompanhante em, pelo menos, uma consulta de pré-natal.

\section{Categorias de Análise}

Os resultados estão organizados em três categorias:- Experiência da mulher em não ter acompanhante na sala cirúrgica; - Experiência do acompanhante em aguardar o nascimento sozinho; e o Poder dos profissionais de saúde sobre a cena do nascimento.

Experiência da mulher em não ter acompanhante na sala cirúrgica

As mulheres sentiram-se apoiadas e seguras durante o trabalho de parto, uma vez que o seu companheiro estava presente o tempo todo. A partir do momento em que foram separadas do seu companheiro, surgiram sentimentos negativos, como medo, insegurança, ansiedade e tensão, pois o procedimento cirúrgico, por si só, torna a mulher um sujeito passivo no processo do nascimento, limitando a sua participação, tornando-a vulnerável às condutas e rotinas institucionais. As falas revelam que a presença do acompanhante, poderia contribuir para que se sentissem mais seguras durante a cesárea.

Eu achei ruim, queria que ele estivesse do meu lado, porque ele me acalmava, eu tinha medo, fiquei deitada, não conseguia ver nada direito, porque não podia levantar a cabeça, tinha um pano na minha frente e minhas mãos estavam amarradas, não podia me mexer direito.(P6)

Eu estava com muito medo, e acho que se o meu esposo estivesse comigo, teria sido mais tranquilo, ele teria me acalmado. (P11)

Bem melhor se ele estivesse ali do meu lado, a gente fica tensa, com medo, desprotegida. (P7)

Na cesárea eu fiquei triste e chateada dele não ter entrado, porque a gente tinha sonhado com esse momento, que estaríamos juntos. (P8)

Para algumas mulheres, o acompanhante não ter entrado na sala de cesárea não foi um problema, pois estavam preocupadas com as condições de nascimento do bebê, com a dor e acreditavam que o companheiro poderia atrapalhar a cirurgia, visto que no parto normal ele poderia participar ativamente:

Eu queria que ele estivesse junto, mas naquela hora eu estava com muita dor, só queria que passasse o mais rápido possível. (P9)

Eu fiquei triste, chateada, mas o importante para mim era meu bebê nascer bem, se ele não podia estar comigo. (P10)

Eu acho que ele não queria ter entrado também, porque o parto normal é bonito, o marido pode participar, das outras vezes ele cortou o umbigo dos nenéns, e agora ele não ia poder fazer nada. (P13)

Mesmo algumasmulheres que relataram estar preocupadas com a saúde do bebê e acreditavam que o companheiro poderia atrapalhar durante a cirurgia, mencionaram se sentirem tristescom aseparação, uma vez quenãovivenciaramo nascimento, como planejado na gestação.

\section{Experiência do acompanhante em aguardar o nascimento sozinho}

Para alguns companheiros, não ter participado do nascimento do seu filho, foi uma experiência que gerou sentimentos negativos como decepção, tristeza e nervosismo, pois a maioria estava vivenciando essa experiência pela primeira vez e a preocupação com a companheira e o desfecho final se fizeram presentes no seu imaginário. Além disso, se sentiram desrespeitados pelos profissionais que não informaram que não entraria na sala cirúrgica, e veria seu filho nascer. 
A enfermeira disse que o médico não tinha deixado. Eu não gostei, fiquei triste, porque eu acho que eu não ia atrapalhar, era só me falar o que eu precisava fazer, e eu queria muito ter visto meu filho nascer. (A10)

Fiquei muito bravo e nervoso, ninguém me chamou, e o parto não demorou 10 minutos, eles fizeram a cirurgia muito rápido. (A6)

Eu fiquei chateado, porque a gente ficou todo tempo junto, aí na hora mais esperada eu não estava lá, eu que sou o pai. (A5)

Alguns acompanhantes, apesar de terem sido excluídos do momento do nascimento sem serem consultados, relataram que preferiam não assistir a cesárea, pois acreditavam que sua presença na sala cirúrgica iria atrapalhar ou prejudicar a assistência à sua mulher e seu filho. Aqueles que já possuíam experiência como acompanhante no parto normal dos outros filhos, também não demonstraram frustração em não participar da cesárea, pois consideraram que não seriam úteis. Isso demonstra que o acompanhante não foi encorajado a participar e tampouco recebeu orientações sobre a importância da sua presença para apoiar a mulher.

Acho meio estranho cesariana, no parto normal eu ajudei, segurava a perna dela, até cortei o umbigo dos nenéns, na cesariana eu não ia poder ajudar em nada, então foi bom sabe, deu tudo certo. Acho que foi melhor não ter visto a barriga dela toda aberta. (A13)

Eu também não queria, porque tinha medo, vai que eu passo mal e só atrapalho. (A8)

Na cesariana eu nem queria ter entrado, porque é muito sangue, tenho um pouco de medo, e como foi tudo de urgência eu não queria atrapalhar nada. (A12)

Só fiquei triste, por não ter ido na cesárea, mas não fiquei bravo, entendo que é um procedimento médico. (A4)

Duas das participantes necessitaram passar por cesárea de emergência, devido ao descolamento prematuro da placenta. As demais cesáreas ocorreram por desproporção céfalo-pélvica, o que não constitui uma emergência obstétrica, sendo assim, haveria tempo hábil de preparar o acompanhante e Ihe orientar sobre seu papel no sentido de dar apoio a sua companheira e não interferir no trabalho da equipe.

A gente ficou apreensivo pela bebê, porque ela (médica obstetra) disse que ia ser meio difícil (a cesárea). (A4)

Fiquei com muito medo de que a neném morresse. (A11)

O nascimento é considerado pelos participantes como um momento único, íntimo e familiar, no qual o casal iria concretizar o que havia planejado ao longo da gravidez, porém, a expectativa não foi atendida. A demora em ver o bebê tanto para a mulher como para seu acompanhante, contribuiu para que sentimentos ruins se exacerbassem:

Nos vimos de manhã no quarto, porque eu fiquei esperando um tempão e ninguém vinha me mostrar o neném, eu apertei na campainha, uma enfermeira disse que estava tudo bem, mas que o neném tinha que ficar um tempo na incubadora, acho que no oxigênio, que não dava de tirar de lá, e disse que era melhor eu ir para casa e voltar de manhã. (A3)

\section{Poder dos profissionais de saúde sobre o nascimento}

Não permitir a presença do acompanhante no momento da cesárea expressa o poder que os profissionais de saúde exercem sobre as rotinas institucionais, considerando que existe uma Lei que deveria ser cumprida. Os acompanhantes relataram que a sua presença no momento do nascimento do filho estava subordinada principalmente à decisão do médico, alguns profissionais de enfermagem também impedirem sua entrada.

A maioria dos entrevistados não recebeu explicação sobre os motivos de não poder entrar na sala de cesárea, e as mulheres também não foram questionadas se gostariam de ter seu acompanhante no momento da cesárea. Essas atitudes demonstram que os profissionais estão de alguma forma tentando isentar, não assumindo a responsabilidade pela tomada de decisão de não permitirem a presença do acompanhante. 
A falta de comunicação da equipe com a mulher e acompanhante durante o procedimento aumentou a ansiedade sobre o bem-estar da mulher e do bebê. O desconhecimento dos participantes acerca da Lei do acompanhante contribui para que o poder dos profissionais fosse exercido com certa naturalidade, resultando na exclusão do acompanhante segundo a conveniência dos profissionais.

Eu acho que o marido da gente tem que participar de tudo, só se a mulher ou ele não queira, mas ninguém pergunta nada para a gente, não sei se isso é normal, ou foi só comigo, porque era cesariana de emergência, ou se era porque era SUS. (P11)

Ninguém me chamou, nem falou nada, quando eu vi, a enfermeira já estava passando com o neném e me chamou para ir junto. (A13)

A enfermeira disse que o médico não deixava. (P10)

Mas sabe como é, o médico não deixa, aí a gente nem discute. (A7)

A enfermeira disse que o doutor não deixou, que eu podia ficar no corredor esperando e na hora que a neném nascesse eu podia acompanhar, mas na sala de cirurgia eu não podia entrar. (A5)

A enfermeira disse que ele não poderia entrar, mas não falou o porquê. (P9)

A atitude passiva da mulher e seu acompanhante contribuem para que os profissionais de saúde exerçam o poder sobre o corpo da mulher e o nascimento, e passem a excluir o acompanhante.

\section{DISCUSSÃO}

Ainda é necessário orientar a mulher sobre os benefícios da presença do acompanhante todo o processo de trabalho de parto e parto. Segundo dados da Pesquisa Nascer no Brasil, 2,7\%(455) das 23.879 mulheres entrevistadas pensavam que a presença do acompanhante no nascimento não era útil, que o mesmo iria deixá-la mais nervosa e apenas 1,4\% disseram que estavam sozinhas porque não queriam ter acompanhante ${ }^{(1)}$.

O pai do bebê tem sido o acompanhante de preferência da mulher, o que favorece o estabelecimento de vínculo afetivo e estimula a paternidade, porém quando o homem é excluído desse contexto, que foi planejado ao longo da gestação, a frustração e sentimentos negativos se fazem presentes,contribuindo de forma negativa para a experiência vivenciada por ambos.A presença do acompanhante nesse momento apresenta inúmeros benefícios, inclusive para a equipe de saúde, pois a mulher se sente mais calma, segura e protegida, e o acompanhante um colaborador importante para o desfecho positivo ${ }^{(18-19)}$.

A necessidade do nascimento cirúrgico tornou a experiência negativa, pois gerou em alguns acompanhantes medo, nervosismo e insegurança, fatores relacionados ao desconhecido. Para alguns participantes a cesárea não é algo normale pode pôr em risco a vida de sua companheira e filho ${ }^{(18)}$.

O comportamento dos profissionais também pode estar relacionado aos aspectos organizacionais, como o fato da instituição não possuir protocolos, e a estrutura física não ter sido planejada para acomodar o acompanhante em todos os momentos. Porém, isso demonstra que os mesmos ainda não estão imersos no cenário da humanização do nascimento ${ }^{(18)}$.

O parto hospitalar oferece pouca ou nenhuma possibilidade da mulher exercitar o poder sobre o próprio corpo e concretizar as experiências em relação ao parto. As parturientes não questionam os profissionais sobre os procedimentos realizados, isso está fortemente ligado a falta de informação sobre seu corpo, processo parturitivo, e pelo medo de ser maltratada pelo profissional de saúde que pode ver esses questionamentos como desrespeito a sua conduta ${ }^{(20)}$.

A submissão da parturiente e de seu acompanhante a ordem dos médicos, fortalece o modelo hegemônico que ainda predomina nas mais diversas áreas da saúde ${ }^{(21)}$. As instituições ainda não estão preparadas para acolher e inseri-lo no contexto hospitalar. Apesar dos avanços no processo de humanização da assistência ao parto ainda há barreiras a serem enfrentadas, entre elas a filosofia assistencial das instituições e a conduta dos profissionais de saúde ${ }^{(10-11)}$. 
O profissional de saúde que presta assistência à mulher deve ter a iniciativa de inserir o acompanhante em todo o processo de parturição e nascimento, pois assim ele se sentirá acolhido e vivenciará a experiência do nascimento de modo positivo ${ }^{(4,18)}$.

\section{CONSIDERAÇÕES FINAIS}

A pesquisa revela que apesar da Lei do Acompanhante estar em vigor há mais de 10 anos, ainda existem barreiras para a inserção do acompanhante na sala cirúrgica, caracterizando uma violação de direitos. A separação da mulher e acompanhante no momento do nascimento desperta em ambos sentimentos diversos, mas a predominância é a insatisfação, apreensão, medo, insegurança e tristeza. De maneira geral, os acompanhantes se sentem excluídos por não terem participado do nascimento de seu filho, como haviam planejado ao longo da gravidez.

Os profissionais de saúde, em especial o médico, e alguns membros da equipe de enfermagem determinam a exclusão do acompanhante na sala de cesárea. A hegemonia médica, conciliada com o desconhecimento da Lei do Acompanhante por parte dos participantes da pesquisa, fortalecem esse tipo de ação, pois os profissionais acreditam serem os detentores do poder sobre o corpo do paciente e definem, assim, tudo o que está relacionado a sua assistência, não respeitando a escolha da mulher. Essas ações compõem uma violação dos direitos da mulher e do casal.

Diante dessa realidade, torna-se necessário a sensibilização dos profissionais de saúde sobre benefícios dessa prática, tanto para a mulher e $\mathrm{RN}$, quanto para a equipe de saúde. A elaboração e implantação de protocolos assistenciais também podem contribuir para que a participação do acompanhante de escolha da mulher seja garantida, em todo o processo parturitivo, uma vez que é um direito garantido por Lei.

Ressalta-se que a equipe de enfermagem, em especial a enfermeira que atua no ambiente cirúrgico, tem papel fundamental para a transformação do cenário atual. Para tanto, precisa reivindicar que a instituição cumpra o previsto em Lei e assuma o papel de mediadora entre os profissionais de saúde e o acompanhante.

Uma das limitações da pesquisa foi à dificuldade dos participantes falarem sobre ocorrido - ato que pode ser decorrente da coleta dos dados ter sido realizada no ambiente hospitalar, por escolha dos participantes, visto que foi dada outra opção de local.

Ainda são necessárias outras pesquisas, com novas abordagens metodológicas, para aprofundar esse tema - a separação da mulher e seu acompanhante na cesárea, uma vez que esse é o cenário onde o acompanhante se faz menos presente, e o nascimento cirúrgico corresponde a mais da metade do número de nascimentos em nosso país.

\section{REFERÊNCIAS}

1. Diniz CSG, D'Orsi E, Domingues RMSM, Torres JA, Dias MAB, Scknek CA, et al. Implantação da presença de acompanhantes durante a internação para o parto: dados da pesquisa nacional Nascer no Brasil. Cad Saúde Pública.[Internet] 2014;30(Suppl. 1) [acesso em 15 de nov de 2016]. Disponível: http://dx.doi.org/10.1590/0102311X00127013.

2. Hodnett ED, Gates S, Hofmeyr GJ, Sakala C. Continuous support for women during childbirth. Cochrane Database Syst Rev. [Internet] 2013;16(2) [acesso em 10 de out de 2016] Disponível: DOI: http://dx.doi. org/10.1002/14651858.CD003766.pub3.

3. Ministério da Saúde (BR). Cadernos Humaniza SUS. Humanização do Parto e Nascimento. [Internet] Brasilia. 2014 [acesso em jun de 2016]. Disponível: http://www.redehumanizasus.net/sites/default/files/caderno_ humanizasus_v4_humanizacao_parto.pdf. 
4. Dodou HD, Rodrigues DP, Guerreiro EM, Guedes MVC, Lago PN, Mesquita NS. A contribuição do acompanhante para a humanização do parto e nascimento: percepções de puérperas.Esc Anna Nery. [Internet] 2014;18(2) [acesso em 04 de set de 2016]. Disponivel:http://dx.doi.org/10.5935/1414-8145.20140038.

5. Brüggemann OM, Koettker JG, Velho MB, Monguilhott JJC, Monticelli M. Satisfação dos acompanhantes com a experiência de apoiar a parturiente em um Hospital Universitário. Texto Contexto - Enferm. [Internet] 2015;24(3) [acesso em 07 set 2016]. Disponível: http://dx.doi.org/10.1590/0104-07072015004220014.

6.Brasil. Lei n. 11.108, de 7 de abril de 2005. Altera a Lei $N^{\circ}$ 8.080, de 19 de setembro de 1990, para garantir as parturientes o direito à presença de acompanhante durante o trabalho de parto, parto e pós-parto imediato, no âmbito do Sistema Único de Saúde - SUS. Diário Oficial da União da República Federativa do Brasil. Brasilia, 7 abr. 2005. Seção 1:1.

7. Brüggemann OM, Oliveira ME, Martins, HEL, Alves MC, Gayesk ME. A inserção do acompanhante de parto nos serviços públicos de Santa Catarina. Esc Anna Nery. [Internet] 2013;17(3) [acesso em 5 de set de 2016]. Disponível: http://dx.doi.org/10.1590/S1414-81452013000300005.

8. CairesTLC, Vargens, OMC. A exclusão do pai da sala de parto: uma discussão de género e poder. Rev. Enf. Ref. [Internet] 2012;3(7) [acesso em 5 de set de 2016]. Disponível: http://dx.doi.org/10.12707/RIII1163.

9. Santos LM, Carneiro CS, Carvalho ESS, Paiva MS. Percepção da equipe de saúde sobre a presença do acompanhante no processo parturitivo. Revista da Rede de Enfermagem do Nordeste. [Internet] 2012;13(5) [acesso em 01 de set de 2016]Disponível: http://www.periodicos.ufc.br/rene/article/view/4079.

10. Vogt SE, da Silva KS, Dias MAB. Comparação de modelos de assistência ao parto em hospitais públicos. Rev Saúde Pública. [Internet] 2014;48(2) [acesso em 02 de out de 2016]. Disponível: http://dx.doi.org/10.1590/S00348910.2014048004633.

11. Brüggemann OM, Ebele RR, Ebsen ES, Batista BD. No parto vaginal e na cesariana: acompanhante não entra: discursos de enfermeiras e diretores técnicos. Rev Gaúcha Enferm. [Internet] 2015;36(n.esp) [acesso em 02 de out de 2016]. Disponível: http://dx.doi.org/10.1590/1983-1447.2015.esp.53019.

12. Ministério da Saúde (BR). Secretaria de Ciência, Tecnologia e Insumos. Protocolo: Relatório de Recomendação: Diretriz Nacional de Assistência ao Parto Normal. Estratégicos: Janeiro/2016.Protocolos Clínicos e Diretrizes Terapêuticas (PCDT) são documentos que visam a garantir o melhor cuidado de saúde possível diante do contexto brasileiro e dos recursos disponíveis no Sistema Único de Saúde. [Internet] Ministério da Saúde: Brasilia; 2016 [acesso em 03 de mai de 2016]. Disponível: http://conitec.gov.br/images/Consultas/2016/Relatorio_DiretrizPartoNormal_CP.pdf.

13. Zampieri MFM, Guesser JC, Buendgens BB, Junckes JM, Rodrigues IG. O significado de ser pai na ótica de casais grávidos: limitações e facilidades. Rev. Eletr. Enf. [Internet] 2012; 14(3) [acesso em 06 de ago de 2016]. Disponível: https://doi.org/10.5216/ree.v14i3.12244.

14. Fontanella BJB, Luchesi BR, Saidel MGB, Ricas J, Turato ER, Melo DG. Amostragem em pesquisas qualitativas: proposta de procedimentos para constatar saturação teórica. Cad. Saúde Pública. [Internet] 2011;27(2) [acesso em 05 de ago de 2015]. Disponível: http://www.scielo.br/pdf/csp/v27n2/20.pdf.

15. Bardin L. Análise de Conteúdo. $5^{a}$ ed. São Paulo: Edições 70; 2011.

16. Friese S. Qualitative data analysis with ATLAS.ti. London: Sage; 2012.

17. Ministério da Saúde (BR). Conselho Nacional de Saúde. Diretrizes e normas regulamentadoras de pesquisa envolvendo seres humanos. Resolução n. 466, de 12 de dezembro de 2012. Brasília; 2012.

18. Souza SRRK, Gualda DMR. A experiência da mulher e seu acompanhante no parto em uma maternidade pública. Texto Contexto - enferm.[Internet] 2016;25(1) [acesso em 08 de nov de 2016]. Disponível: http://dx.doi. org/10.1590/0104-0707201600004080014.

19. Antunes JT, Pereira LB, Vieiras MA, Lima CA. Presença paterna na sala de parto: expectativas, sentimentos e significados durante o nascimento. Rev enferm UFSM. [Internet] 2014;4(3) [acesso em 08 de set de 2015]. Disponível: http://dx.doi.org/10.5902/2179769212515. 
20. de Aguiar JM, d'Oliveira AFPL. Violência institucional em maternidades públicas sob a ótica das usuárias. Revista Comunicação Saúde Educação. [Internet] 201;15(36) [acesso em 12 de set de 2016] . Disponível: http:// dx.doi.org/10.1590/S1414-32832010005000035.

21. Weber D. Medical Hegemony. Int J ComplementAltMed[Internet]2016;3(2) [acesso em 22 de out de 2016]. Disponível: http://medcraveonline.com/IJCAM/IJCAM-03-00065.pdf. 